\title{
'Oh Gawd, How am I Going to Fit Into This?': Producing (Mature) First-year Student Identity
}

\section{Greer Cavallaro Johnson}

Centre for Applied Language, Literacy and Communication Studies (CALLCS),

Griffith University, Nathan Q41 11, Australia

\section{Glenice Watson}

Centre for Applied Language, Literacy and Communication Studies (CALLCS), Griffith University

This paper aims to improve the understanding of some aspects of campus life faced by a mature student and to help inform institutional strategies for enhancing student retention. The 'fit' between students' production of their own identity and their perception of the successful student (both academically and socially) in their institution/ programme of choice is considered to be a significant factor in student retention. While the concept of identity can be variously specified, identity as a production, something that is available for use, and embedded in some social activity, is the conceptual approach taken here. This paper demonstrates how identity as a [mature] first-year teacher-education student is produced by interaction in the course of an interview narrative. A microanalytic discourse analysis of the sequential nature of the interview talk is used to display successive instances of the social production of [mature] first-year student identity, displaying movement towards a better ' $f i t^{\prime}$ with the institution/programme of choice.

Keywords: student retention, discourse analysis, interviews, identity, matureage students

The 'fit' between students' production of their own identity and their perception of the successful student (both academically and socially) in their institution/ programme is considered a significant factor in student retention (Kuh, 2001 / 2; Thomas, 2002; Tinto, 1993). Thomas (2002: 431) notes: 'If a student feels that they do not fit in, that their social and cultural practices are inappropriate and that their tacit knowledge is undervalued, they may be more inclined to withdraw early' (emphasis added). Kuh (2001/2: 25) observes similarly: 'The prevailing view is that students who "fit" or are comfortable in, and affirmed by, the larger institutional culture are more likely to be satisfied and stay in school [university]'. Significantly, it is the 'fit' between the student's identity production and their perception of the successful or enculturated student in their institution and programme of study that is important in their retention by the institution. One way to access whether or not students fit into a particular university culture is to focus research on the way students describe themselves as they go about their university activities. This paper aims to improve the understanding of some aspects of campus life faced by a mature student. Hopefully the discussion of this 
one instance, when combined with findings from other qualitative and quantitative research, will help inform institutional strategies for enhancing student retention.

\section{Background to the Study}

This paper reports on one facet of an ongoing project in a Faculty of Education in an Australian university that aligns with McInnis and James' (1995) university type 'suburban university'. Therefore we use 'Suburban University' as a pseudonym to preserve the anonymity of the participants. The project has as its general aim the enhancement of student retention, satisfaction and achievement. Other aspects of the project have been reported elsewhere, namely: student readiness for university (Watson et al., 2002), relatedness to field of study (Watson et al., 2004), and the gap between university affordances and student uptake of them (Watson \& Johnson, 2003). The analytic approach taken in these papers could be described as 'macro' in that general characteristics of the student population were examined through a variety of techniques including statistics, content analysis, and identification of categories of behaviour.

\section{Theoretical Framework: Understanding the Construction of Identity Through Microanalysis}

Here, we examine a range of topics discussed by a mature-age student and an interviewer for understandings about the construction of programme related identities through the social practice of talking. The theoretical approach taken accords with Widdicombe's (1998: 191) definition that 'identity is available for use: something that people do which is embedded in some other social activity'. Our understanding of the status of interview talk confirms that identity is a negotiated process that takes place during the speakers' 'artful use of talk' (Baker, 1997). The basic premise to this conversation-analysis approach is that during interviews speakers competently conduct social action, such as achieving particular identities, which are constituted out of the interview context itself. Therefore we do not take the conventional social-science approach where the interviewee is treated as reporting 'truthful' answers to the interviewer's questions about a reality that exists outside the interview. Rather, we use a situated approach in that '[1]anguage comes to be seen as a resource for describing states and assembling social realities in particular, setting- and listener-relevant ways' (Baker \& Johnson, 1998: 230). In other words, the identity that the student produces is related to, and dependent upon, the interview context, and this necessarily includes the interviewer's dual role as speaker and listener (Mishler, 1986).

The data that inform this paper are drawn from two interviews: one held at the end of orientation week in semester one, followed by another early in semester two. The student (along with several peers) self-selected in response to the researchers' general request to an orientation-week cohort of students in a pre-service education programme for participants in the ongoing faculty project. The general aim of these particular interviews was to evaluate the impact of an extended orientation week programme designed to enhance students' enculturation into the university. To encourage openness, the interviews were conducted by an experienced research assistant who had no academic or social connection 
to the students. The interviewer prompted stories and anecdotes through various invitations for background, expectations and feelings but, for the most part, allowed the participants to tell their own story and place their own emphases on aspects of it that were important to them. The participant whose interviews provide the data for this paper provided particularly clear instances of self-identification that warranted closer analysis, and thus identity became the focus through which the aims of the project could be realised. Interviews were audiotaped and transcribed using conversation analysis conventions (Jefferson, 1984). However, to facilitate readability, a minimal set of transcription notation was used. We have chosen to focus on some communicative aspects of the data and not others, thus acknowledging that transcription is not a neutral activity (Ochs, 1979).

In the present paper, we turn to a 'micro' analytic technique to provide more nuanced understandings of those aspects of student life of interest to a particular mature-age, first-year student. The analysis is methodologically and practically motivated (see Paoletti, 2000). The demonstration of how student identities are produced through talk in interaction is an innovative method through which to contribute to understanding students' concerns, which in turn might support practical efforts to retain students.

In our analysis we treat the data as an interview that contains some of the characteristics of narratives (see Mishler, 1986). In particular, we focus on the evaluative nature of the interview talk because we are interested in gaining a clear understanding of speakers' points of view of the topics covered (see Page, 2002). Evaluative talk is an example of how particular ways of organising talk shape identity. In a similar manner we apply some of the tools of ethnomethodology, particularly membership categorisation analysis (MCA) and also aspects of conversation analysis (CA) to the interviews as means of systematic analysis. Therefore we highlight instances where the speakers build central membership categories (Sacks, 1992) in the talk. For example Hester and Eglin (1997: 3) explain that:

Membership categories, as defined by Sacks, are classifications or social types that may be used to describe persons. By way of illustrations an occasioned list of such categories may include 'politician', 'gravedigger', 'pimp', 'nerd', 'astronaut', 'skinhead', 'boozer', 'former boy scout leader' and 'grandmother'.

Adapting Baker's (1997: 142-3) practical advice for arriving at the categorisations in a systematic manner, we have located central categories that underpin Ewan's talk (coolest old bloke), and worked through the 'activities' that either Ewan or the interviewer associate with the categories (flirting) in order to fill in the attributions that are made to each of the categories. Finally, we look at the categories and the attributes as evidence of how categories of actors do, could or should behave (flirting has helped the coolest old bloke to fit into the academic community).

The analytic concern is to describe the interactional production of identity so as to achieve the overall aim of the paper: to improve understanding of some aspects of campus life faced by a mature student and to help inform institutional strategies for enhancing student retention. Attention to those membership categories used by the interviewer and the interviewee, often in evaluative commen- 
tary on events and issues that happen in relation to the university course, produces an in-depth perspective of the identity of a [mature-age] university student.

The above description and rationale for our choice of analytic methods has assumed a 'bottom-up' approach to the data (Johnson, 1999). That is, we begin with a close reading of the data and confine our commentary, in the first instance, to the talk in interaction, referring to aspects of the talk such as the use of continuers, response tokens and extreme-case formulations where appropriate.

Although the following information is not relied upon in the analysis, unless it is referred to directly or indirectly in the talk, we provide the reader with some background knowledge that the members in the talk could have been aware of, to varying degrees, when they began their interview talk. The cohort of students ( $N$ $=142$ ) from whom the participants were drawn was $79 \%$ female, $57 \%$ school leavers (aged 17 to 19) and 38\% first-generation university students (that is, no member of their immediate family had attended university). The participant whose interviews provide the data for this paper was Ewan, a 34-year-old male who did not self-identify with any particular ethnic or indigenous grouping. Ewan is a pseudonym used to preserve the anonymity of the participant. The interviewer is identified as ' $\mathrm{I}$ '. The interview conducted at the end of orientation week is identified as 'Interview 1', and the interview early in semester two as 'Interview 2'. Numbering on excerpts of interview relates to turn-taking in the original complete interview. Having supplied this description, we intend to introduce this 'top-down' information into our discussion only after we have conducted a bottom-up analysis, as a means of linking context built up inside the interview to the outside institutional context.

\section{Producing a Successful Student Identity}

Ewan produces his successful student identity through activities we have labelled retrospecting, lacking fit, changing views, being successful (Ewan's view), and being successful (the reported views of others).

\section{Retrospecting}

Ewan begins to self-identify from the start of the first interview (turns 1-33), which we will identify as 'Segment 1' and summarise as follows. Our summary is offered as a prelude to our interactional microanalysis; as a way of supplying some background to where Ewan had 'come from' before coming into teacher education at Suburban University. At all times throughout the interviews the interviewer hands over the floor to Ewan after prompting him to supply part of the story being sought. Although it might at first appear that Ewan maintains a high degree of tellership to a passive, but clearly interested listener (Ochs \& Capps, 2001), it must be acknowledged that the questions that the interviewer asks do delimit much of the nature and extent of what gets said. In response to the interviewer's request to tell about his background, Ewan tells a troubled story indicated by comments such as 'I didn't like the person I'd become', so taking 'time out to discover who I was' and then professing the 'need to look for something different'. His decision to enrol in education was the result of professional counselling that his first choice of psychology was not appropriate because ' $\mathrm{I}$ 
have enough ... troubles dealing with myself let alone taking on ... someone else's problems'. So he 'decided well instead of helping people at one end of the spectrum go to the beginning of the spectrum and encourage kids because my own experience as a child was not nice'. He noted that as a student he 'had a lot of problems at school with peers and ... bullying and so on', that in year 12 he 'was just a person who made up the numbers' and that he 'had no intention of going into tertiary study from the end of year 12 '. Since leaving school he has worked in 'sales positions' and 'owning my own business'. These isolated quotes that come at the start of the interview could suggest that, at the beginning of his course at least, Ewan was not fully invested in the educational enterprise of becoming a teacher. Rather, it could be assumed that he was seeking a new direction in life.

Building on Sacks (1972), Hadden and Lester (1978: 335) note that 'people identify themselves in a variety of ways, on different occasions, and with different purposes at hand (i.e. they create the availability of employing alternative membership categorisation devices)'. At the start of his (first) interview Ewan produces an identity of an unsuccessful student at a past point in time. However, since interviews are co-constructed, communicative events, it must be acknowledged that this identity is at least in part produced by the interviewer's choice of question. As we will show, his orientation to this identity is relevant, in so far as it constructs a contrast with one produced later in the interview. At the start he contextualises himself as a student but at the same time differentiates himself from a successful version of that identity (Hadden \& Lester, 1978). The image of himself that he talks into being is that of a school student who was set apart from his peers for a number of reasons that are not fully explained.

\section{Lacking fit}

In segment 2 (below), Ewan responds to a different request from the interviewer to talk about his feelings on the first day of his orientation-week activities. This request offers an opportunity for producing a different student identity from the one in his description of himself at school.

\section{Interview 1: Segment 2}

(34) I:

(35) Ewan:

(36) I:

(37) Ewan:

(38) I:

(39) Ewan: yeah and um and so it was like a sea of all these young people and thinking oh what are their thoughts of having an old you know old bloke sitting in their room with them um I suppose there was enthusiasm as well [um I was keen to get the process started and I was trying to keep in a um some attitudes of enthu- 
siasm um enjoy the experience keep my mind open enough to

(40) I: enjoy it not let anything

(41) I:

[mm

(43) Ewan: that came about me in that week not to let that disrupt my my thought patterns and so forth just to enjoy it and and whatever negative came out of it not sit and dwell on it but just look at it deal with it and let keep going on and have a great time.

(See Appendix for the transcription notation.)

This interview segment explores Ewan's feelings on arrival at the university at the beginning of orientation week. The interviewer opens with the conversational strategy 'yeah how did you feel on Monday morning ((the first day of $\mathrm{O}$ Week))?', thus encouraging an adjacent conversational move that Maynard (1991) describes as a perspective display series: originally seen as a device used by clinicians to seek out and then listen, without interruption, to a client's perspective so as to respond with appropriate advice or information. In Ewan's case, such a move by the interviewer encourages his assessment or evaluation of anything that he might wish to tell about his first week at university. He quickly establishes that he was uneasy about how he was going to 'fit'. As is shown in Segment 2, the interviewer does listen, delivering minimal response tokens, before offering the information that Ewan's perspective of his early days has been contradicted in her communications with younger students. Such a countermove by the interviewer, to set aside fears about not fitting in, is effectively ignored. Ewan's continuing preoccupation with integration versus segregation in educational encounters, in Segments 1 and 2 of Interview 1, offers a degree of 'global coherence' (Agar \& Hobbs, 1982) to his narrative accounts 'through repetition of examples making this same general point' (Mishler, 1986: 242). His orientation this time is not however with his fit into the institution per se but with the 'sea of young faces' (turn 37). He reiterates this at turn 39 with 'a sea of all these young people' and is concerned with what they might think of an 'old bloke sitting in their room'. Thus he is producing an identity through a stage-of-life category, mature age, through a use of contrast pairs: young people versus old bloke. By the pronominal use of 'their' to describe the common teaching space he sees the 'room' as belonging to the young people and himself as not fitting into it. 'Mature-aged students' are characterised as people who 'managed to stand to the side and not be noticed so much' and this time he self-identifies as one of a group instead of being completely alone, as he was at high school.

In all, Ewan makes eight direct references to his maturity (and numerous implied ones) throughout this interview. When we introduce some institutional discourse here (background knowledge of which the participants in the talk could have been aware), what is remarkable about this preoccupation with his lack of fit because of his maturity is that only just over half of the cohort are school leavers and approximately a fifth of the cohort are aged 30 or older (he is 34). At turn 39 he also identifies his gender (in conjunction with his age) as an 'old bloke'. As Archer et al. (2001) confirm in their work on mature-age identity and issues of educational access, masculinity can be conceptualised usefully 'as multiple, fluid and shifting' (p.432). In this instance, gender and age identities intersect. For this 
cohort of education students being an 'old bloke' is a much more significant identifier than being 34 years old, because four-fifths of the cohort are female. In a later interview Ewan pays more attention to this when he has realised the advantage of being male in the student population.

In both Segments 1 and 2 Ewan reports that he was uneasy in his respective educational contexts. However, in his account of being a mature-age student (Segment 2) he contrasts his 'uneasy' feeling with other feelings of 'enthusiasm', and a determination to 'enjoy the experience' and to 'keep my mind open enough to enjoy it' (turn 39).

\section{Changing views}

As part of the project referred to earlier, an extended orientation-week programme had been introduced which had as its aim the improved enculturation of the students into the institution. The orientation programme included information-giving sessions about the programme and courses, sessions with student mentors, a faculty lunch, and workshops with various support elements of the university such as Learning Assistance, Student Services and Information Services (for further discussion of this see Watson \& Johnson, 2003). Ewan had been an enthusiastic participant in the various activities of orientation week. The following segment (Segment 3) is a response to the interviewer's request for him to tell of any changes in his feelings about being a mature-age student in a sea of young faces. Once again this question opens things up and invites an evaluation of events. In the following segment we see a shift in Ewan's identity production from a concern with lack of fit because of his mature age to a focus on the skills he needs to become what he perceives to be a successful student. At this stage he rates his more specific concerns with being able to put in the necessary hours and having sufficient 'computing skills' as a more tellable part of his story (Ochs \& Capps, 2001).

Interview 1: Segment 3

(43) I:

(44) Ewan:

(45) I:

(46) Ewan:

(47) I:

(48) Ewan: ok I'll come back in a moment to experiences on those individual days but now you're at the end of orientation week how are those feelings now what's changed (.) what's the same um a lot of the fears I had have been dispelled um I suppose the one thing I've realised I I was under no illusion that I would have to work but probably the level or the amount of hours that I'll have to put in has changed like and skills that I don't have such as computing skills um I know that I'm going to have to put time and effort into practice at home just to do the basic get basic skills before I even start tackling work requirements so I' $m$ there are some areas that I've got to improve outside of of my study environment just to get meself myself into a position to handle yep

what's going on so

tell me about that workload what what level did you anticipate before you started

oh look I anticipated that um you know we'd have our contact 
time and then we'd probably have to do the similar sort of contact similar to what the contact time outside of the contact

(49) I: time a couple of hours on each subject a week

(50) Ewan: and to know that that was probably a quarter of their expectation um and then even even hearing um things like from the student mentors who were saying well that's ok if you actually enjoy that course that you're going to do if you don't enjoy it you're going to have to do probably even more hours.

Ewan self-identifies in Segment 3 as having a shortfall between his perception of the time commitment and that expected by university staff. He also points out his lack of computing skills. The assumption underpinning this identification is that he is orientating to a desire to fit in with his perceptions of the expectations and statements of staff concerning an enculturated student. That is, such a student would know how many hours of work need to be done and would have acquired the prerequisite computing skills to start work. Once again there is global coherence to the story in so far as Ewan is producing an identity that is keen to fit in and much of his talk is taken up with assessing and evaluating the circumstances in which he now finds himself.

\section{Being successful (Ewan's view)}

In his first semester of education studies, Ewan progressed from seeing himself as 'just a person who made up the numbers' at high school to one who successfully completed the university semester with credits in each of his four subjects. It could also be assumed that the description of his new self at university means that he feels he now has something substantial to offer compared with a silence involved in making up the numbers in high school. Following is a segment from his (second) interview conducted at the beginning of semester two. Segment 4 opens with the interviewer's further request to hear more of his university life story:

Interview 2: Segment 4

(3) I: um tell me about life at ((Suburban University)) so far

(4) Ewan: oh fabulous

(5) I: yep

(6) Ewan: yeah I cannot speak highly enough of of my experience so far in the university life I've just had the best of time

(7) I: $\quad$ mmhmm

(8) Ewan: yeah it's fabulous

(9) I: ok anything that has to come out straight away before you before I ask you things in order

(10) Ewan: oh I've the experience has just been (.) ah it's probably been more challenging than I thought but in in doing that that's probably even more exciting

(11) I: $\quad$ mmhmm

(12) Ewan: because if it was a boring repetitious I'd be disinterested and gone whereas I'm engaged 
(13) I: ok

(14) Ewan: absolutely engaged [in the course

(15) I:

[what's been some of the biggest challenges

I mean you were expecting it to be challenging from the first interview

(16) Ewan: yes I was um

(17) I: $\quad$ why is it more so

(18) Ewan: ah because being mature-age I came with a whole heap of world experiences and prior knowledge which some have been very beneficial but quite a lot of that has also been unlearning to unlearn the learning I've got

(19) I: ok

(20) Ewan: and to see things from a progression that what I'd learnt 2030 years ago has no longer a relevancy in the way I learn so

(21) I: do you mean a learning style a content area

(22) Ewan: yeah learn-all all you know and I'm finding that again even in the beginning of this semester again that I'm going to have to relearn um the strategies um the combinations of my thinking and so on so so it's ah I suppose that's where it's been a bit challenging ah I've probably recognised some things which I'm trying to change for this semester as well.

It is clear from this excerpt that Ewan evaluates himself as having had a very positive experience in his first semester in education studies. He uses a number of superlatives or extreme case formulations (Pomerantz, 1986) such as 'fabulous', 'the best of time' as descriptions of the course and these utterances help to convey the highly tellable nature of the story (Ochs \& Capps, 2001). He still makes reference to his maturity but now constructs it in terms of category-bound activities related to learning styles, of needing to 'unlearn the learning' surrounding much of his 'world experiences' and 'prior knowledge'. The fact that he lists advantages then disadvantages in that order and with that emphasis is not a coincidence. This organisational pattern of his talk highlights the negative disposition he attaches to his 'world experiences' and 'prior knowledge'.

\section{Being successful (the reported views of others)}

Much of Ewan's identity production as a successful student clearly comes from his evaluation of his academic and social relationship with his fellow students. Earlier it was noted that Ewan aligned himself with the mature-age students who stood to the side with a group of mature-age peers and tried not to be noticed; now he sees himself as having a role based on his equality in his mixed-age study group:

Interview 2: Segment 5

(206) Ewan: yeah no I in our study group there's probably half mature age and half 17 going 18

(207) I:

ok

(208) Ewan: and ah and I've learnt a heap from the 17 going on 18 
(209) I:

(210) Ewan:

(211) I:

(212) Ewan: in fact they've got a world that they can contribute to my life and and so on and and I feel that that's mutual they've felt the same way as one said to me you're the coolest oldest bloke I've ever met

(213) I:

(214) Ewan:

(215) I:

(216) Ewan:

(217) I:

(218) Ewan:

(219) I:

(220) Ewan:

mmhmm

and I've they've said they've also learnt a heap from me and I don't exclude any suggestions from them on the basis that they don't know anything

$\mathrm{mm}$

(heh heh)

so I take that as an absolute compliment from them yeah

and so I'm able to engage with any student I don't go I don't understand what you' re talking about in this language I try and identify and become involved in their life and ah yeah

tell me a bit more about this coolest oldest bloke identity how do you how much do you identify as a mature-age student here at ((Suburban University))

oh I I think it's more I feel it physically like you know I was worn out last night um mentally I think I'm the biggest kid probably on the campus

mmhmm

um you know um the comment was said yesterday because I'd just had I just abounded with happiness yesterday and they said you're contagious and I said fabulous let's go let's enjoy the ride there's no point coming here going oh God another day.

Instead of standing to one side and wondering about whether or not he will fit in he has made a space for himself with others in the course. He says, 'I try and identify and become involved in their life.' Ewan is clearly pleased now with the identity he assumes is being ascribed to him by his younger peers. He recalls a fellow younger student's description of him, in direct reported speech, as 'one said to me you're the coolest oldest bloke I've ever met' (turn 212). He subsequently confirms this identity by naming himself as 'the biggest kid probably on the campus' (turn 218). He not only fits into 'their' world - he has acquired some agency and respect there as well. At this stage the contrast pairs (young vs old) heard in earlier segments have become relational pairs constituting one category, student. Their relationship is built on mutuality rather than competition, as seen in turn 212. Here, as elsewhere, Ewan acknowledges the debt he owes to younger students and he confirms this perspective with his negativity about his prior learning. The explicit link between the two categories is summed up in the attribute 'coolest' that displays the ability to go with the flow and be accepted.

As acknowledged earlier, much of Ewan's identity production as a successful student clearly comes from his academic and social relationship with his fellow students. Another aspect of this identity is produced in the following segment (Segment 6), where his talk centred on talking about the value in being a 'bloke', not just mature-aged. 
(236) Ewan: $\quad$..um being that there's hardly any males in my course well I'm getting to flirt and play up like a two-bob watch like I never have I've never flirted this much in my life

(237) I:

(238) I:

[(heh) yeah

(239) Ewan:

mmhmm

(240) I:

so again it's been a whole new set of social skills together for me as well

(241) Ewan: because I have to cos I find myself in tute groups where I'm the only bloke

(242) I:

(243) Ewan: and so um so it's certainly taken some barriers away where I talk honestly and openly

(244) I: right

(245) Ewan: whereas you know if there was a few more boys in the room I'd probably be a bit more blokey than what I am in some of the classes

(246) I: yeah

(247) Ewan: it's a whole different social construct at times for me.

It is the mix of social and academic identity work that is of interest in Segment 6. For the first time in the interviews Ewan produced his identity in terms of gender, and the gender aspect relates more to the social learning than to the academic (turn 239), although the two are connected. He explains that his 'learning' in tutorials includes 'getting to flirt and play up like a two-bob watch' (turn 236). In saying so he also identifies himself in terms of sociability. However, he no longer names himself as mature-age explicitly. These are category-bound activities that are as readily attributable to the young as they are to mature-age persons, of either gender. Sacks (1974) has pointed out that members are often 'positioned' at particular stages of life (e.g. youth, mature age) and these positions are hierarchical with some categories displaying higher status than others. In his prior talk throughout the interviews, Ewan has valued the activities of the young students. University is seen as their place. Now, especially in turn 236, he is attributing the characteristics he valued in young students to himself as a means of describing the student he has become. It could reasonably be assumed that at this stage of the interview Ewan is rejecting an orientation to a 'mature-age identity' that was invited explicitly by the interviewer in turn 217. In turn 241 he turns from the topic of flirting to being the only bloke in tutorials and how this allows him to be less blokey than he might be with his male peers. Such a change of topic is not explicitly invited by the interviewer, via a specific question. However it is worth at least speculating how this change of topic might have been subtly influenced by the interviewer's minimal responses, especially the elongated 'mmhmm' (turn 238). This response just might have reminded Ewan of the serious status of the interview enough for him to change the topic from sociality to academic work.

By the end of the second interview Ewan has talked into being a different iden- 
tity from the one produced in Segment 1, where he gave some background to his high-school experiences before entering Suburban University after working for some years. His talk is now characterised by a sense of confidence, optimism and sustained enthusiasm for the future. The repeated point of Ewan's story is that with some effort the mature-age student can not only fit into a culture that appears to be populated by the young but also enjoy student life in a learning process marked by mutuality in terms of social experience and academic knowledge. In Ewan's case, gender identity has superceded mature-age identity, accruing a different, more comfortable, institutional fit for a student who is not a recent school leaver.

\section{Concluding Comments}

As stated earlier, the analysis presented in this paper is methodologically and practically motivated. Our treatment of two narrative interviews has shown some of the activities and social practices that constitute the identity of a first-year mature-age, teacher-education student. We have conducted a microanalysis of interview talk, thus demonstrating how a successful student identity can be predicated on the following category-bound activities: computer literacy; realistic understanding of the workload required to learn effectively and complete assessment tasks; acceptance of the need to unlearn some skills gained in the past, and engaging positively with younger students in social and academic learning. The production of successful student identity is demonstrated through a process of retrospecting, lacking fit, changing views, being successful (Ewan's view), and being seen as successful (the reported views of others). The interview process has afforded the opportunity for the student to reflect on the changes that have occurred between the interviews. However, when we take the methodological premise into account, that interview talk can contribute to identity formation, it might well be that the interviews themselves contributed to the student's perception and development of his better fit within the university.

The interview process itself has been shown to be important since it not only offers a chance to hear a story, but it also allows the storyteller time to reflect and thereby adjust their production of who they are at this point in time. We have demonstrated how this process is a means for students to formulate and reformulate identities through their use of language in interaction with an interested listener. As Baker (1984) found in her ethnomethodological work with interviews between adolescents and an adult talking about adolescence, this has been an opportunity for this student to reach different conclusions about himself from those that might be reached by others outside the interview. Being a successful mature-age student has been both a 'topic' for discussion and an 'interactional accomplishment' that takes place in the interview (Baker, 1984: 321). Therefore, from a practical perspective, we recommend the use of interview narratives as opportunities for students not only to tell institutions who they are becoming, but also to articulate this shifting process for themselves. Hence it becomes a public and a private enterprise. The practical outcome of such detailed analytical work is its potential to contribute more nuanced understandings for institutions engaged in the enduring problem of student retention. 
It must be remembered that by its very nature the telling of a narrative is contingent upon the speakers' points of view (Riessman, 1993). Therefore we readily acknowledge that the story that Ewan tells is not a mirror of the truth that exists as an 'objective reality' in the world outside the interview (Mishler, 1990: 427). In electing to talk about some aspects (and not others) of his life as a new student, this storyteller highlights some of his concerns that are related to the purpose of the interview. We have traced his concern with fitting into the institution through a focus on the global coherence of his narrative (Agar \& Hobbs, 1982): he returns again and again to his point of view, the need to fit in. A further test regarding the generalisability of the findings for us is to continue to collect more and more stories in order to make longitudinal comparisons. By extension, Ewan's concerns might be linked to those of others in his programme of study or even more generally to the student population.

\section{Acknowledgment}

We thank Elizabeth Stevens, who is working as Senior Research Assistant on this project, interviewing, transcribing and locating sections of spoken data. The project was funded by a Griffith University Strategic Improvement Grant in 2002.

\section{Correspondence}

Any correspondence should be directed to Dr G.C. Johnson, Centre for Applied Language, Literacy and Communication Studies, Griffith University, Nathan Q 4111, Australia (g.johnson@griffith.edu.au).

\section{References}

Agar, M. and Hobbs, J.R. (1982) Interpreting discourse: Coherence and the analysis of ethnographic interviews. Discourse Processes 5, 105-31.

Archer, L., Pratt, S.D. and Phillips, D. (2001) Working class men's constructions of masculinity and negotiations of (non)participation in higher education. Gender and Education 13 (4), 431-49.

Baker, C.D. (1984) The 'search for adultness': Membership work in adolescent-adult talk. Human Studies 7, 301-23.

Baker, C.D. (1997) Membership categorization and interview accounts. In D. Silverman (ed.) Qualitative research: Theory, Method and Practice (pp. 130-43). London: Sage.

Baker, C.D. and Johnson, G. (1998) Interview talk as professional practice. Language and Education 12 (4), 229-42.

Hadden, S. and Lester, M. (1978) Talking identity: The production of 'self' in interaction. Human Studies 1, 331-56.

Hester, S. and Eglin, P. (1997) Culture in Action: Studies in Membership Categorisation Analysis. Washington, DC: International Institute for Ethnomethodology and Conversation Analysis and University Press of America.

Jefferson, G. (1984) Transcription notation. In J.M. Atkinson and J. Heritage (eds) Structures of Social Action. Studies in Conversation Analysis. Cambridge: Cambridge University Press.

Johnson, G.C. (1999) Telling tales: A complicated narrative about courtship. Narrative Inquiry $9(1), 1-23$.

Kuh, G. (2001/2) Organizational culture and student persistence: Prospects and puzzles. Journal of College Student Retention 3 (1), 23-9.

Maynard, D. (1991) The perspective display series and the delivery and receipt of diagnostic news. In D. Boden and D. H. Zimmerman (eds) Talk and Social Structure: Studies in Ethnomethodology and Conversation Analysis (pp. 164-92). Cambridge: Polity. 
McInnis C. and James, R. (1995) First Year on Campus: Diversity in the Initial Experience of Australian Undergraduates. Canberra: AGPS.

Mishler, E.G. (1986) The analysis of interview narratives. In T.R. Sarbin (ed) Narrative Psychology: The Storied Nature of Human Conduct. New York: Praeger.

Mishler, E.G. (1990) Validation in inquiry-guided research: The role of examplars in narrative studies. Harvard Educational Review 60 (4), 415-42.

Ochs, E. (1979) Transcription as theory. In E. Ochs and B.B. Schieffelin (eds) Developmental Pragmatics (pp. 43-72). New York: Academic.

Ochs, E. and Capps, L. (2001) Living Narrative: Creating Lives in Everyday Storytelling. Cambridge, MA: Harvard University Press.

Page, R. (2002) Evaluation in childbirth narratives. Discourse Studies 4 (1), 99-116.

Pomerantz, A. (1986) Extreme case formulations: A way of legitimizing claims. Human Studies 9, 219-29.

Paoletti, I. (2000) Being a foreigner in primary school. Language and Education 14 (4), 26682.

Riessman, C.K. (1993) Narrative Analysis. London: Sage.

Sacks, H. (1972) An initial investigation of the usability of conversational data for doing sociology. In D. Sudnow (ed.) Studies in Social Interaction. Englewood Cliffs, NJ: Prentice Hall.

Sacks, H. (1974) On the analysability of stories by children. In R. Turner (ed.) Ethnomethodology. Harmondsworth: Penguin.

Sacks, H. (1992) Lectures on Conversation (edited by G. Jefferson ) Oxford: Blackwell.

Thomas, L. (2002) Student retention in higher education: The role of institutional habitus. Journal of Education Policy 17 (4), 423-42.

Tinto, V. (1993) Leaving College: Rethinking the Causes and Cures of Student Attrition (2nd edn). Chicago: University of Chicago Press.

Watson, G. and Johnson, G. (2003) Filling the Gaps: Students' Perceptions of University Affordances. 7th Pacific Rim Conference: First Year in Higher Education, Brisbane, July. On WWW at http: / / www.qut.edu.au/talss / fye/ papers.htm. Accessed 08.08.03.

Watson, G., Johnson, G. and Austin, H. (2004) Exploring relatedness to field of study as an indicator of student retention. Higher Education Research and Development 23 (1).

Watson, G., Johnson, G. and Billett, S. (2002) Ready or not? Results of an Orientation Week Survey of Education Students. 6th Pacific Rim Conference on First Year in Higher Education, Christchurch. On WWW at http://www.qut.edu.au/talss/fye/previouspapers.htm. Accessed 08.08.03.

Widdicombe, S. (1998) Identity as an analysts' and a participants' resource. In C. Antaki and S. Widdicombe (eds) Identities in Talk (pp. 191-206). London: Sage.

\section{Appendix: Transcription notation}

((laugh)) transcriber description

[ overlapping utterances at this point

(.) untimed pause 